\title{
Estefanofilariose em humanos: ocorrência e mecanismos de transmissão
}

\author{
Stephanofilariasis in humans: occurrence \\ and transmission mechanisms
}

Antonio Pereira de Novaes ${ }^{1}$ e Alexandre Takeshi Miyashita ${ }^{2}$

\begin{abstract}
RESUMO
Descreve-se aqui o encontro do helminto Stephanofilaria spp., em dermatite nodular ulcerativa em seres humanos, sendo as ulceras pesquisadas de dimensões variadas e com alguns anos de existência. Acredita-se que, a presença desse parasita, que afeta diversas espécies de animais domésticos e silvestres, possa agravar o quadro com as lesões produzidas nos vasos venosos e linfáticos, reduzindo a circulação, retardando a cicatrização. $O$ ciclo deste parasita no ser humano, também é descrito.
\end{abstract}

Palavras-chaves: Dermatite nodular ulcerativa. Stephanofilaria spp.

\begin{abstract}
This work describes the occurrence of the helminth Stephanofilaria spp in ulcerative nodular dermatitis in humans. The ulcers observed presented a variety of sizes and some years of existence. It is believed that the presence of this parasite, which affects several domestic and wild animal species, may harm human health through lesions produced in venous and lymphatic vessels that reduce blood circulation and retard the healing process. The cycle of this parasite in humans is also described.
\end{abstract}

Key-words: Ulcerative nodular dermatitis. Stephanofilaria spp.

A Stephanofilaria é um helminto, que afeta animais domésticos e silvestres ${ }^{12689}$ promovendo lesão denominada dermatite nodular ulcerativa. Os vetores normalmente citados são moscas, que transportam mecanicamente as formas larvares denominadas microfilárias de uma ferida para outra. As lesões podem ocorrer em diversas partes do corpo do animal, e são de difícil tratamento ${ }^{2368}$, devido à obstrução dos vasos sanguíneos e linfáticos, que os parasitas promovem, podendo essas lesões perdurarem por anos seguidos. 0 mecanismo de transmissão por moscas não está bem definido e, nem pode ser aplicado ao homem, pois na ocorrência de dermatite nodular ulcerativa na espécie humana ${ }^{3} \mathrm{em}$ úlceras varicosas (Figura 1 e Figura 2). a pessoa afetada, tem o cuidado de proteger a ferida com curativos e bandagens. Assim, as moscas não têm acesso à lesão, para depositar as formas larvares do parasita.

Nos bovinos, a Stephanofilaria spp apresenta-se nos folículos pilosos e também nas papilas dérmicas. Para atingir esses sítios, a via de acesso seria a circulação sanguínea, através da inoculação das formas larvares, por insetos picadores ${ }^{10}$.

Para testar essa suposição, com o objetivo de esclarecer a presença de formas larvares da Stephanofilaria spp, em lesões ulceradas em seres humanos, delineamos os seguintes experimentos preliminares, realizados nos Laboratório do Centro Nacional de Pesquisa em Instrumentação Agropecuária- Embrapa, com material colhido no Hospital Municipal de Ibaté SP, e no Centro de Saúde da mesma cidade.

Para verificar a presença de microfilárias daStephanofilaria spp na superfície da epiderme, que poderia ser uma via de acesso do parasita para a úlcera, em um grupo de dez pessoas, saudáveis, com idade entre 20 e 50 anos, que não estavam afetadas por dermatite nodular ulcerativa. Com uma fita adesiva transparente, foi coletado material por compressão da pele na região da tíbia, em seguida colou-se a fita em uma lâmina, para ser observada ao microscópio. Com aumento de 400X e com auxílio do zoom

1. Consultor da Embrapa Instrumentação Agropecuária, São Carlos, SP. 2. Médico da Prefeitura Municipal de Ibaté, Ibaté SP.

Endereço para correspondência: Dr. Antonio Pereira de Novaes. Embrapa Instrumentação Agropecuária, Rua XV de Novembro, 1452, Caixa Postal 741, 13560-970 São Carlos, SP.

Tel: $55163374-2477$

e-mail: novaes@cnpdia.embrapa.br

Recebido para publicação em 8/5/2006

Aceito em 17/1/2006 


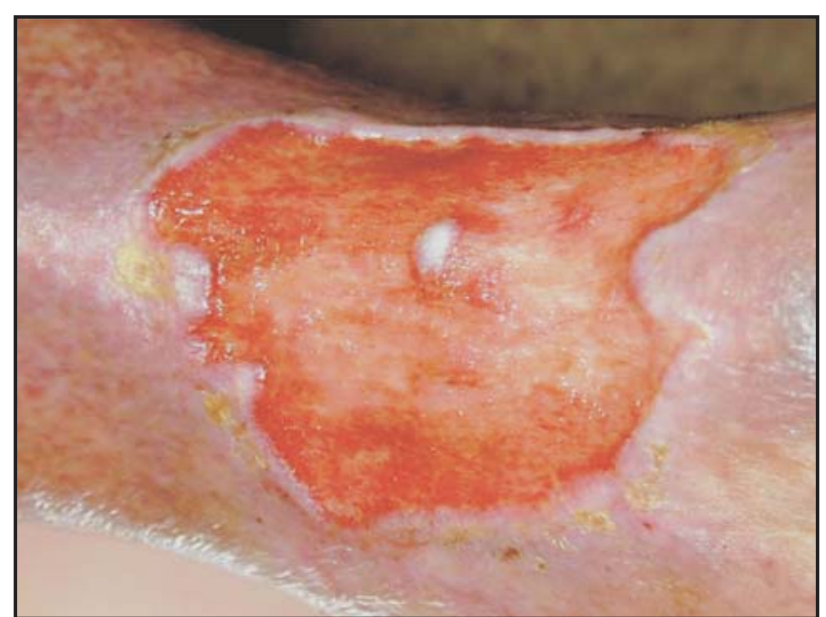

Figura 1 - Dermatite nodular ulcerativa (úlcera varicosa indolente) em ser bumano.

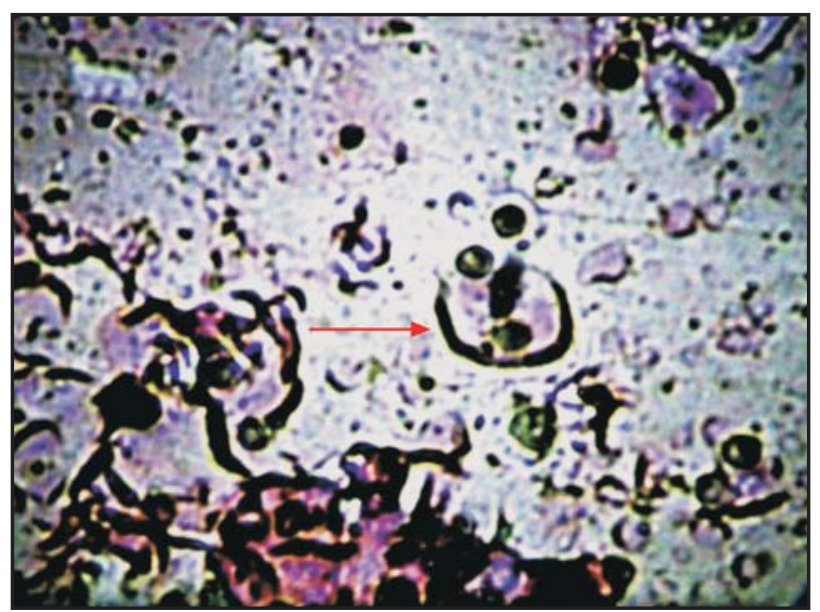

Figura 2 - Fotomicrografia obtida de esfregaço de material colbido de dermatite nodular ulcerativa em ser bumano, mostrando formas larvares e filamentosas da Stephanofilaria spp (Aumento de $400 \mathrm{X}$ mais 5X zoom, da câmera).

da câmera fotográfica eletrônica em 5X foi possível visualizar formas larvares e adultas da Stephanofilaria $s p p^{5}$ (Figura 3). 0 que poderia explicar a presença do parasita na superfície da pele e no folículo piloso ${ }^{10}$.

Para verificação de formas larvares, deste parasita na circulação sanguínea, neste grupo após a perfuração do dedo indicador com agulha, foi coletado uma gota de sangue periférico, com a borda de uma lâmina de vidro. Fazendo-se um esfregaço. visualizou-se no esfregaço ao microscópio,com aumento de 400X mais 5X o zoom da câmera, microfilárias (Figura 4).

Para verificar a possibilidade da transmissão transplacentária, fez-se esfregaço de sangue da circulação periférica, coletado de cinco bebês recém nascidos, no momento da colheita de material para exame de fenilcetonúria (teste do pezinho). (Obs: esses bebês eram filhos de mães não portadoras de úlceras). 0 material colhido foi observado ao microscópio com aumento de 400X mais 5X o zoom da câmera fotográfica, observando-se a presença de microfilárias. 0 mesmo ocorrendo com esfregaço de sangue colhido do cordão umbilical no momento do parto.

Conclui-se, portanto, que a presença de microfilárias na epiderme, na circulação sanguínea periférica em todos os

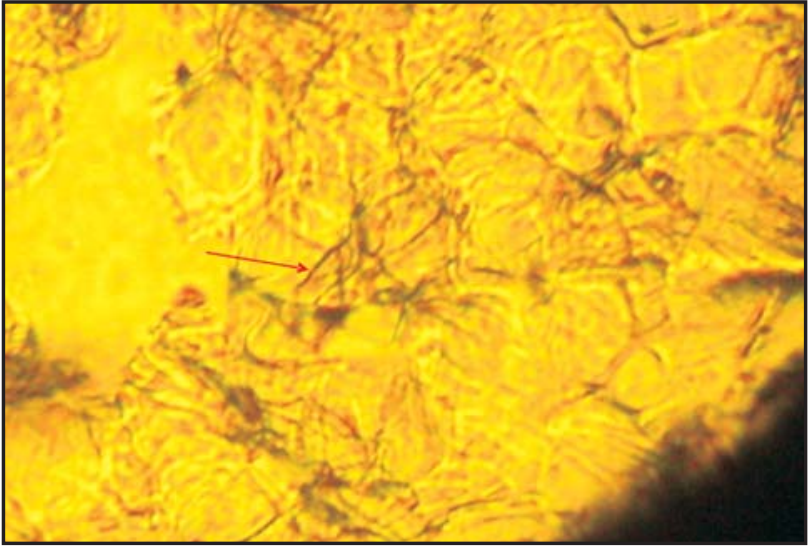

Figura 3 - Fotomicrografia de impressão da pele em fita adesiva transparente, visualizando-se microfilárias em forma filamentosa. (aumento de 400X mais 5X o zoom da Câmera Fotográfica).

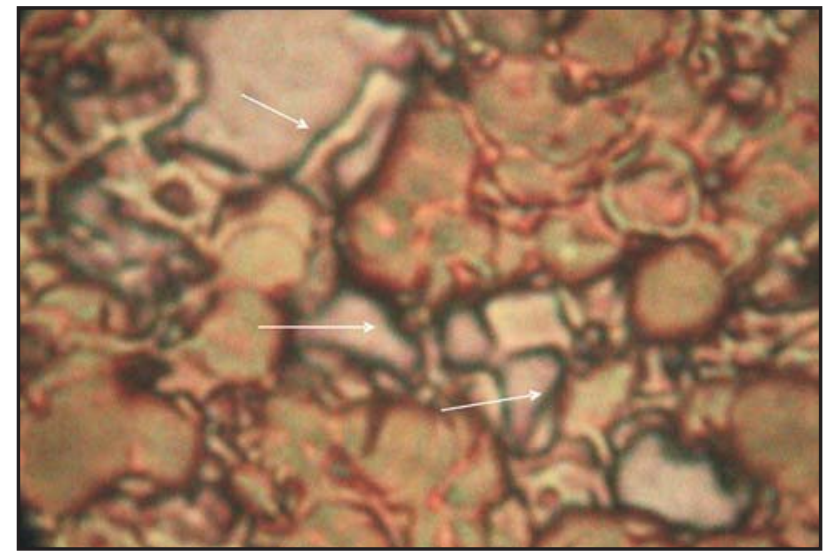

Figura 4 - Fotomicrografia de sangue periférico Visualizando-se microfilárias em forma filamentosa (aumento de 400X mais $5 \mathrm{X}$ com o zoom da Câmera Fotográfica).

casos analisados, confirma a suposição que os vetores da estefanofilariose, são na realidade mosquitos ${ }^{10}$ que veiculam esses parasitas na espécie humana e acreditamos, que o mesmo ocorra nos animais. Cabe lembrar, que esse vetor, é o mesmo da elefantíase e da oncocercose no homem. Assim, as formas de transmissão não diferem entre esses filarídeos.

Desta forma, supõe-se que após uma lesão na pele, as larvas da Stephanofilaria spp, presentes na circulação periférica, invadem o ferimento e ali se instalam, podendo, comprometer a recomposição dos tecidos na cicatrização. A visualização de microfilárias no sangue periférico de recém nascidos e no cordão umbilical, apontam a via transplacentária como um provável mecanismo de transmissão das formas larvares, deste parasita, da mãe para filho.

A ocorrência de úlceras afetadas pela estefanofilariose no ser humano, pode ser considerada como um fato grave, pois afeta milhares de pacientes. É causa de mal estar e depressão nas pessoas afetadas, impedindo as atividades cotidianas. Assim, mais pesquisas devem ser realizadas, para trazer mais luz ao tema, pois o controle deste parasita, pode trazer grande benefício social. 


\section{REFERÊNCIAS}

1. Fadzil N. Infeccción por Stephanofilaria kaeli em bovinos de la peninsula de Malásia: incidência Y tratamiento. Noticias Medico-Veterinarias, Leverkusen, volume 1, p. 44-52, 1997.

2. Gill BS, Balakrishnan P, Lumsden GG, Jones PG. Treatment of stephanofilariosis ('earsore') whith ivermectin. Veterinary Parasitolology 40: 159-163, 1991.

3. Novaes AP. Filariose nos animais domésticos. Vet News, Rio de Janeiro 52: 6-8, 2001

4. Novaes AP. Estefanofilariose e dermatite nodular ulcerativa em cães: relato de caso. Revista de Educação Continuada do Conselho Regional de Medicina Veterinária de São Paulo, São Paulo, volume 8, fascículo 2, 2005.

5. Novaes AP, Bagnato VS, Miyashida AY, Flores FLE, Kurrachi C. Estefanofilariose: uma zoonose. Embrapa Instrumentação Agropecuária (Série Documentos 21), São Carlos, SP, p.1-14, 2006.
6. Novaes AP, Costa AJS, Barbosa RT, Morera DP, Ruzza FJ. Dermatite ulcerosa em bovinos provocada por Stephanofilaria. Pesquisa Agropecuária Brasileira 23: 927-929, 1988

7. Novaes AP, Miyashida AY. Estefanofilariose: uma zoonose: vetores e mecanismos de transmissão. Embrapa Instrumentação Agropecuária (Série Documentos 22), São Carlos, SP, p. 1-11, 2006.

8. Novaes AP, Sena MCO, Moreira DP. Stephanofilaria sp associada a casos de pododermatite em bovinos leiteiros. Foot-rot in dairy cattle associeted whit Stephanofiaria sp. Arquivos de Biologia e Tecnologia 33: 575-579, 1990.

9. Oba MSP, Sinhorini DL, Novaes AP, Costa AJS, Dell Porto A. Stephanofilaria em bovinos do município de São Carlos, Estado de São Paulo.In: Anais da $32^{2}$ Conferência Anual da Sociedade Paulista de Medicina Veterinária, Pirassununga, SP, 1977.

10. Smith HA, Jones TC. Patologia veterinária. Union Tipográfica Editorial Hispano Americana. México, p.537,538, 1962. 